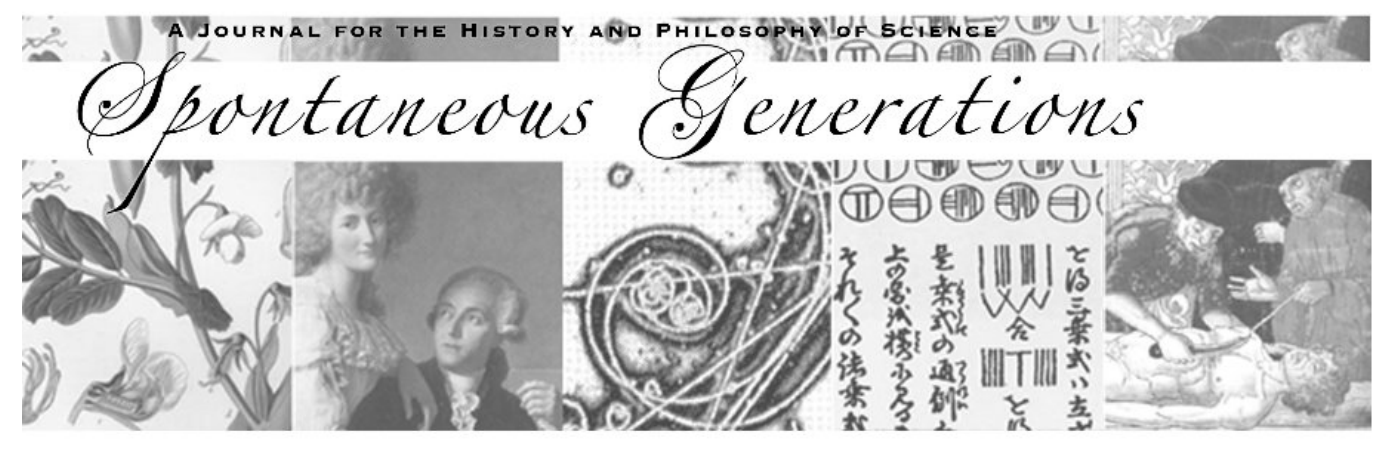

On the Subject of Goethe: Hermann von Helmholtz on Goethe and Scientific Objectivity

Author(s): Dani Hallet

Source: Spontaneous Generations: A Journal for the History and Philosophy of Science, Vol. 3, No. 1 (2009) 178-194.

Published by: The University of Toronto

DOI: $10.4245 /$ sponge.v3i1.6568

EDITORIAL OFFICES

Institute for the History and Philosophy of Science and Technology

Room 316 Victoria College, 91 Charles Street West

Toronto, Ontario, Canada M5S $1 \mathrm{~K} 7$

hapsat.society@utoronto.ca

Published online at jps.library.utoronto.ca/index.php/SpontaneousGenerations

ISSN 19130465

Founded in 2006, Spontaneous Generations is an online academic journal published by graduate students at the Institute for the History and Philosophy of Science and Technology, University of Toronto. There is no subscription or membership fee. Spontaneous Generations provides immediate open access to its content on the principle that making research freely available to the public supports a greater global exchange of knowledge. 


\title{
Peer-ReVIEWed
}

\section{On the Subject of Goethe Hermann von Helmholtz on Goethe and Scientific Objectivity*}

\author{
Dani Hallet ${ }^{\dagger}$
}

\begin{abstract}
In their recent book, Objectivity, Lorraine Daston and Peter Galison oppose the image of the scientist as a rational, objective, and dispassionate investigator of nature with that of the intuitively guided and emotionally volatile artistic genius. The authors argue that the emergence of objectivity as an epistemic virtue in nineteenth-century scientific practices was intimately tied to a newly perceived threat to knowledge: that of the subjective self. In their discussion, Daston and Galison cite the artist's creative imposition of ideas on the world as quintessentially subjective and opposed to science.
\end{abstract}

This paper will examine Hermann von Helmholtz's conception of the virtuous scientist, focusing primarily on two papers written on the subject of Goethe's scientific work and its relation to science proper. In working out a coherent picture of Helmholtz's scientific and epistemological commitments, it will become apparent that his guiding image of the virtuous scientist did not map onto the scientific personas described by Daston and Galison. The particular position occupied by Helmholtz brings into question their claims that structural objectivity arose in response to the failings of mechanical objectivity, and that the opposition between the objective and subjective can be characterized as one between passive and active research methods.

\section{Preliminaries and a Brief History of OBjectivity}

In 1853 Hermann von Helmholtz wrote disparagingly of Johann Wolfgang von Goethe's scientific investigations: "Instead of trying to arrange the phenomena of nature under definite conceptions, independent of intuition, he sits down to contemplate them as he would a work of

*Received July 2009. Revised paper accepted October 2009.

†Dani Hallet received her Bachelor's in philosophy from the University of British Columbia where she is now working on her Master's in history and philosophy of science through the Interdisciplinary Program. Her research interests include post-Kantian science in Austria and Germany with an emphasis on Neo-Kantian science and philosophy in the nineteenth century. She is currently working on a project concerning Goethe's scientific legacy in the nineteenth century and the formation of scientific personas and historical narratives. 
art, complete in itself, and certain to yield up its central idea, sooner or later, to a sufficiently susceptible student" (Helmholtz 1853, 46). What did Helmholtz mean by this and why was he, one of Germany's most prestigious scientists at the time, concerned with the scientific researches of one who, as he himself claimed, was first and foremost, a poet? (Helmholtz 1853, 45). The meaning of this question is the question of this paper. As we will see, the reasons for Helmholtz's concerns are complex and multifaceted. The "ghost of Goethe" cast its shadow over several mid-century scientists who sought to instate a new era of experimental science in German universities and differentiate themselves from the science of the previous generation. For the purposes of this paper I take Helmholtz's concerns about Goethe to be indicative of a particular conception of how to do science properly which took the artist- exemplified by Goethe-as their point of departure. In this paper I will show how Helmholtz's concerns over what he considered an artistic approach to nature reveal insights into how he conceived of the properly objective, scientific approach to investigations of nature. He was not alone in his particular framing of the purposes and methods of science and he did not stand alone in his characterization of Goethe as a potential threat to experimental science. I will use his conceptions of the artist and of the scientist to motivate concerns about the history of objectivity as offered by Lorraine Daston and Peter Galison in their recent book, Objectivity (2007). I will argue that the various threats to objective knowledge that nineteenth-century scientists were responding to cannot be characterized simply under the rubric of a passive scientific subject and that the history of objectivity cannot, in the first instance, be understood as a response to the threat of an active, subjective self.

In Objectivity, the authors contrast nineteenth-century conceptualizations of the scientist as a rational, objective, and dispassionate investigator of nature with those of the intuitively guided and emotionally volatile artistic genius. According to the authors, epistemic virtues $^{2}$ like objectivity, understood as internalized norms that guide investigative practices, arise out of epistemic anxieties-worries about the certainty or truthfulness of knowledge (Daston and Galison 2007, 49). The authors argue that the emergence of objectivity as an "epistemic virtue" in nineteenth-century science was intimately tied to a newly perceived threat to knowledge-that of the subjective self (191-251). In their discussion

\footnotetext{
${ }^{1}$ This phrase is borrowed from the title of Nicholas Jardine's 1997 paper "The Mantle of M'uller and the Ghost of Goethe: Interactions between the Sciences and Their Histories."

2"Epistemic virtues" as employed by the authors are "norms that are internalized and enforced by appeal to ethical values, as well as to pragmatic efficacy in securing knowledge."(Daston and Galison 2007, 40-41)
} 
of the threat from subjectivity, Daston and Galison contrast the artist's creative imposition of ideas on the represented world with the scientific investigation of nature, which aimed at removing the subject from the processes of inquiry and instead let nature "speak for herself" (191-251). They claim that the artist was understood at the time to be an extreme form of a more general wilful self that had been made possible by Kantian philosophy. This Kantian subject was understood according to a model in which the self was arranged around an active will and possessed ideas that it imposed upon nature.

The scientist's solution to anxieties about subjectivity was mechanical objectivity-an epistemic virtue that aimed at eliminating the influence of the self upon the object of investigation. Various practices were involved in realizing this ideal: using photography instead of drawing, refraining from manipulating data sets, and abstaining from commentary on images. By adopting the ideal of objective knowledge as their goal and engaging in these practices, Daston and Galison argue that nineteenth-century scientists were positioned against artists who strove to insert their subjective biases into their representations of nature (245-46). The ideal of mechanical objectivity contributed to the rise of a new epistemic virtue-that of structural objectivity (Daston and Galison 2007, 250). Mechanical objectivity required that scientists present their observations and data without interpretation, allowing the particular facts to speak for themselves. Before too long it was realized that particulars could not, on their own, stand for an entire class of entities, much less lead to laws of nature with broad scope. Structural objectivity was intended to bring investigation away from particulars and into an enduring world of persistent relations, be they logical, syntactical, mathematical, or systems of sensory signs. Scientists and philosophers saw in formal systems of invariant relations a way of guaranteeing the ability to share knowledge. This satisfied the new requirement for objectivity, which de-emphasized the requirement of an accurate portrayal of nature and put the onus on communicability.

In adopting the ideal of structural objectivity scientists sought assurance of objective validity in structural relations between phenomena that held invariantly for all rational investigators over all times. Daston and Galison trace this notion of objectivity to Kant's notion of Mittheilbarkeit (communicability) as it appears at the end of the first Critique, "on the grounds that if a judgement can be communicated to other rational beings, there is a solid (though not infallible) presumption that they are talking, and talking accurately, about the same object" (262). Thus, according to the authors, Kantian philosophy offered simultaneously both the conceptual materials for a willful subjective self and the possibility of objective knowledge. Daston and Galison offer this characterization as one that 
could be, and was in fact, read from Kant. Its value as an interpretation of Kantian philosophy is tangential to the argument presented in this paper. ${ }^{3}$ In interpreting the history of objectivity I am concerned with whether this vision of Kantian philosophy, with its emphasis on communicability, was adopted and endorsed by nineteenth-century thinkers. Daston and Galison argue that this was the case and that part of the drive to embrace this notion of objectivity was the "vertiginous violence" that came with the nineteenth-century boom in sensory physiology, experimental psychology, and the burgeoning social sciences. This swell of research revealed new disparities across the perceptual and cognitive processes between individuals, and across situations, leading to worries about shared experience and shared knowledge (Daston and Galison 2007, 256). The subjectivity threat countered by structural objectivity was that of a scientific self cloistered and sealed in a solipsistic fortress (Daston and Galison 2007, 267). Structural objectivity was a move away from the ideal of interpretation-free representations of nature and toward the construction of abstract systems that would be valid, in the words of Max Planck, for scientists "of all places, all times, all peoples, all cultures" (Daston and Galison 2007, 254).

According to Daston and Galison, these two notions of objectivity, structural and mechanical, followed on the heels of an out-going eighteenth-century ethos which they call "truth-to-nature," that took the world of phenomena to be rich with ideas that must be sought out and interpreted by the active scientific mind (59-63). The basic idea was that nature was patterned according to archetypes that lingered latent below the surface of transitory and seemingly chaotic particulars. The scientist committed to this ethic saw nature as presenting a deceptive front that required careful probing to obtain a truthful interpretation of natural phenomena. These eighteenth-century scientists worried about a passive self being taken in and tricked by a coquettish nature. Both mechanical and structural objectivity are positioned against this ethic in Daston and Galison's account insofar as the properly objective scientist is understood as a passive or non-interventionist observer and the truth-to-nature scientist an active interpreter (203, 223-31). The ambition of this paper is to add some details to this brief history of objectivity, details which will require us to reconsider certain aspects of the argument in

\footnotetext{
${ }^{3}$ This reading emphasizes communicability as a hallmark of objectivity and does not commit itself to the formal structures of knowledge that Kant thought grounded and made possible objectivity. It allows for a wide variety of epistemic codes to be characterized as broadly Kantian in their commitment to structures and communicability more generally speaking without taking on the whole architectonic of transcendental philosophy. It should not be mistaken as the considered philosophical views on Kant of the authors or the scientists in question.
} 
Daston and Galison's book. As mentioned, for this purpose I will look to one of Germany's leading and most prolific nineteenth-century scientists: Hermann von Helmholtz. It is unsurprising that Helmholtz appears in two sections of Objectivity, as he was arguably Germany's most prominent scientist in the nineteenth century, and wrote widely on a variety of scientific and philosophical topics. Daston and Galison open their chapter on structural objectivity with an account of Helmholtz's sign theory of sensation as a precursor to the positivist theories of structural objectivity that would follow at the turn of the twentieth century. They also employ Helmhotlz in another chapter discussing the scientific subject. In serving in these roles he appears in two different lights: as a scientist committed to structural objectivity, and as scientist worried about the imposition of a willing self on scientific knowledge. These roles are not prima facie disparate, but as we will see, a fuller appreciation of the concerns that motivated his set of epistemic virtues will lead to some puzzling questions about Daston and Galison's account of objectivity. The concerns I wish to focus upon may be approached by looking at two papers Helmholtz wrote on the scientific work of Johann Wolfgang von Goethe: "On the Scientific Researches of Goethe" (1853) and "Goethe's Anticipation of Subsequent Scientific Ideas" (1892). Both papers addressed the question of what constituted proper science by opposing it to art in the context of Goethe's work in morphology, botany, and optics. I will supplement the Goethe papers with some of Helmholtz's scientific and epistemological writings, in order to question Daston and Galison's claim that objectivity arose in the nineteenth century in response to anxieties centered on a passivity or an activity of the scientific self. I take Helmholtz's views to be relevant to this topic insofar as his views on science were widely influential well into the twentieth century. A close look at his worries about Goethe can reveal the details of one instance of the oft assumed dichotomy between art and science. In doing so I hope to suggest that the boundaries of disciplines, especially the methodological ones, do not simply follow from definitions of their projects, rather their projects and methods are articulated through discourses and practices that often differentiate themselves in relation to conceptions of other practices within specific political and cultural contexts.

\section{The Eyes of Goethe}

In 1853 Helmholtz argued that Goethe's work was not properly scientific because he looked at nature with the intuitive eyes of the artist, which led to two inexcusable faults: 1 ) failing to grasp causal relations, and 2) neglecting to articulate precise and definite theories. Science was in the business of coming up with laws, and scientific laws, to Helmholtz's mind, were highly generalized formulas that specified in precise terms the 
invariant causal relations between phenomena. His criticisms of Goethe culminated in the accusation that "he saw by happy chance that there was a law, and he followed up the indications of it with great shrewdness. But what law it was, he did not see; nor did he even try to find it out" (Helmholtz $1853,49)$. Which is to say, in the context of a discussion of the artist's morphological studies, that Goethe failed to seek the causal connections behind common morphological structures in a properly experimentally rigorous way. Helmholtz advocated an "experimental interactionist" conception of science, in which one began with generalizations about experience and then manipulated variables to see what remained constant over varying experimental conditions, refining the initial hypothesis until it was a precise expression of the unexceptional relations behind a broad and well-defined domain of objects. Laws were simply more generalized facts. In an 1862 paper, "The Facts in Perception," the facts were the "observable lawlike relationships between [the] appearances" (Helmholtz 1878, 141). These factual or lawful relations were objective because they reflected the structure of those elements of phenomena that did not vary under changing conditions-experimental, inter-subjective or otherwise. Objective knowledge may have been so in virtue of the structures of "the actual" world but, epistemologically speaking, it was signaled by its ability to be communicated intersubjectively over time, that is, invariably. Objective knowledge of the relational structures of phenomena was not something that one could simply take as given in describing things haphazardly. One knew they had such knowledge when it was clearly communicable across a variety of subjects and a range of situations. It was not in virtue of being incommunicable that a piece of knowledge was not objective, but if it was non-communicable over some instances and persons there was a good chance that it was not an objective fact.

The standard for precision was set by mathematicized laws like those in Newtonian physics or the measurable wavelengths in Helmholtz's "Physiological Causes of Harmony in Music" (1857). These were highly communicable formulations that everyone, if given the requisite training, could understand. Helmholtz contrasted this with the elitist je ne sais quoi of artistic insight. He encouraged the reader to try to define scientifically the leaf-like appendage of Goethe's Urpflanze, ${ }^{5}$ arguing that at best one can make a vacuous statement about the parts of flowers being "lateral appendages of the axis [...] to see this does not require

\footnotetext{
${ }^{4}$ I have taken this description of Helmholtz's position in the philosophy of science from Heidelberger 1994.

${ }^{5}$ The Urpflanze was Goethe's notion of an archetypal plant form upon which all species of plants were derived. It was, for him, an idea that existed in nature that was not strictly ideal but observable to those with adequate observational abilities.
} 
Goethe" (Helmholtz 1853, 47). The point is supposed to be that attempts to systematically define the Urpflanze resulted in ludicrous, vacuous statements about stems and stalks. As soon as one tried to communicate what was meant by the Urpflanze it became clear that one was not talking about something that could be referred to in scientific discourse-it was either nonsense or outside the domain of science. The ineffability of Goethe's intuitions disallowed the sharing of his insights in a way that promoted subsequent investigations. Lacking the capacity to be equally understood by members of the scientific community, this kind of intuitive knowledge could not possibly be properly objective. ${ }^{6}$ Goethe's failure to develop exact, communicable, causal explanations for natural phenomena made him an inadequate scientist and this, Helmholtz maintained in 1853, was a function of his artistic character.

However, Helmholtz did not understand Goethe to be an impetuous, recklessly passionate romantic, a caricature too often associated with Romanticism for reasons too complex to discuss here. Rather, he saw in the poet's work a reluctance to probe nature and a preference instead for passive observation. He saw this reluctance to probe nature especially in the poet's optical work and characterized Goethe's rejection of Newtonian theory as a battle in a larger war against experimental methods (Helmholtz $1853,46)$. Unlike certain understandings of artistic intuition as an active creative process, Helmholtz took it to be a form of passive cognition (Hatfield 1991, 197). He claimed that the epiphany at Lido in which Goethe first grasped the Urtypus was a typical instance of passive artistic intuition (Helmholtz 1853, 38; 1892, 488). Passivity, however, did not entail deception. In the same way that we can recognize proper grammatical constructions without knowing the explicit rules involved, so too could art present generalizations recognizable as true of our experience. ${ }^{7}$ However, the process by which these intuitive truths were grasped was not available to reflection and was not explicitly and actively worked out like the propositional inductive theories of science. These theories, according to Helmholtz's account, specified with mathematical rigor their domain of objects and then through meticulous accumulation of observations from experiments drew conclusions about broad causal relations between them. Though art was sufficient for generalizations that captured phenomenal experience it was not so for scientific knowledge, which must be

\footnotetext{
${ }^{6}$ To illustrate this comparison Helmholtz cited the opposition between Goethe's work in optics and that of the community of experimental physicists, who all, "without exception, agree" on the validity of Newtonian optics. The objective certainty of the Newtonian theory was evident by the agreement of physicists based upon mathematical theorems that could be shared and understood by all. Lacking communicability, a theory could not be considered properly objective.

${ }^{7}$ For a fuller discussion of Helmholtz's classical theory of aesthetics, see Hatfield 1994.
} 
demonstrably true everywhere and always, that is, objective. Helmholtz accused Goethe's artistic vision of tainting his work in science not by way of active Romantic zeal but through the passivity that Schiller attributed to "the naïve poet."

Helmholtz's 1892 paper, "On Goethe's Anticipation of Subsequent Scientific Researches," differed in tone, but little in content. He continued to consider artistic intuition a passive process through which the artist grasped general truths about macrocosmic experience (Helmholtz 1892, 492). But he was less hostile to artistic cognition, admitting that intuitions are often the first step in a scientific project, claiming even that art was "another way, besides that of science, to acquire insight into the complicated workings of nature" (Helmholtz 1892, 481). He argued that in this respect Goethe anticipated certain contemporary scientific theories and he cited the poet's work as less precise anticipations of his own theory of sensation and law of conservation of force (Helmholtz 1892, 495-99). Nevertheless, Helmholtz continued to distinguish scientific work from that of the artist in virtue of the ability of the former to reveal causal relations in terms of explicit laws. The two main points of 1853-that scientific knowledge got at causal relations and that it was expressed in explicit, communicable formulations-remained, with the emphasis weighted differently so to portray Goethe in a more comradely light. ${ }^{9}$ In both 1853 and 1892 Helmholtz bemoaned Goethe as a failed scientist, not because his overly active, romantic will projected itself onto his representations of nature, as one might have expected from reading Daston and Galison's discussion of the romantic subject and its juxtaposition with the objective scientist. Rather, it was Goethe's passive observational approach, which simply assumed nature there as given,

\footnotetext{
${ }^{8}$ For more on this classification of Goethe and his relationship with Schiller see Richards 2002, 430-34.

${ }^{9}$ There is the question of why Helmholtz would have changed at all in his portrayal of Goethe between 1853 and 1892. This is a complex question that has been given much scholarly attention. It is generally understood as a symptom of the wider metamorphosis in Helmholtz's thought. Some scholars attribute it to changing political conditions in the German academia at the time. By the later half of the nineteenth century, science was no longer the underdog in the universities, battling for pride of place in the stuffy world of tradition that favoured more artistically inclined disciplines, including speculative Naturphilosphie. The promotion of experimental science in academia and beyond had been a wild success. So much so, argues Timothy Lenoir, that the re-appropriation of Goethe can be attributed to a reaction on the part of moderate liberal scientists like Helmholtz, to a crass and overly pragmatic 'Americanization' of academia (Lenoir 1994, 172). Still other authors, like Gary Hatfield and Michael Heidelberger, look more to the internal workings of Helmholtz's thought, which see him reacting to new scientific work and the tensions within his own epistemological position. Heidelberger's analysis of the development of Helmholtz's notion of lawfulness is particularly useful here. See Heidelberger 1994, especially sections II and III.
} 
that was the source of his scientific shortcomings. The artist assumed that the truths of nature could be simply observed by a sufficiently subtle mind, "Instead of trying to arrange the phenomena of nature under definite conceptions, independent of intuition, he [Goethe] sits down to contemplate them as he would a work of art, complete in itself, and certain to yield up its central idea, sooner or later, to a sufficiently susceptible student" (Helmholtz 1853, 45-46). In this, Helmholtz claimed that Goethe shared a "secret affinity" with Hegel and Schelling (Helmholtz 1853, 46). Here we glimpse what Helmholtz took to be the primary source of error in the artistic approach to nature: the assumption that the mind has open access to the world of phenomena, an assumption he attributed also to the Naturphilosophen. In attributing this shared trespass to the idealist, as exemplified by Hegel, and the Naturphilosoph as exemplified by Schelling, Helmholtz seems to conflate two distinct philosophical positions (Helmholtz 1853, 46). It should be noted that it is only a particular version of Hegelian idealism that Helmholtz seems to take issue with. Michael Heidelberger has argued convincingly that Helmholtz was importantly in line with the Fichtean version of idealism (Heidelberger 1994, 482-91). Helmholtz's concerns do not lie with idealism and Naturphilosophie as such, but rather with the idea that the mind has access to the world of things through unanalyzed intuitions, which he sees the Hegelian idealist and the Naturphilosoph as endorsing.

\section{The Real Ideal Threat}

Much has been written on Helmholtz's campaign against idealist philosophies of nature. ${ }^{10}$ From early on in his career he scorned Naturphilosophie and all "speculative metaphysics" on the basis of what he saw as their unwarranted and often false use of ideas in natural science, such as the Lebenskraft of his Berlin teacher Johannes Müller. ${ }^{11}$ Helmholtz wrote to Emil Du Bois-Reymond in 1864, "Grown up among the traditions of high-flown metaphysics, I have learned to value the reality of facts in opposition to theoretical probabilities" (Lenoir 1997, 130). Timothy Lenoir maintains that Helmholtz's early work in physiology was a "concerted attack" on the idea of a Lebenskraft, and that his 1847 "Memoir on the Conservation of Force" can be read as an assault on similar assumptions. It was read that way at the time, as is clear from its rejection as materialistic and democratic by some of the old guard in German academia (Lenoir 1997, 130).

\footnotetext{
${ }^{10}$ See Lenoir 1997, "Politics of Vision," Jurkowitz 2002, "Helmholtz and the Liberal Unification of Science", and Cahan 1994 "Civilizing Power of Science."

${ }^{11}$ For more on Müller's role in the lives of his students, see Jardine 1997.
} 
Helmholtz was not alone in his rebellion against the entrenched dominance of Naturphilosophie. During his student years in Berlin, he joined a Naturforscheverein-natural scientists' club-where young scientists such as Du Bois-Reymond, Rudolph Virchow, and Ernst Brücke collectively swore against allowing any talk of vital forces to creep into their work and instead adhered strictly to the lexicons of chemistry and mechanics. These young men saw themselves as a reforming, if not revolutionary, vanguard of an experimentalist science ${ }^{12}$ that was to be the new foundation of German academia and that was to unify German society under the banner of liberalism. They saw close connections between the proper epistemological orientation for science and the social, political and psychological requirements of a rationally ordered state (Jurkowitz 1997, 292). The question of how to be a properly objective scientist had political implications for these budding scientists and continued to as their careers unfolded. Their epistemic credos were largely built around a mission to remove Naturphilosophie with its "reference to authority and unbounded speculation" (Jurkowitz 1997, 292) from its position of privilege in German academia and set experimental science in its place.

For Helmholtz, the fundamental methodological problem of Naturphilosophie to be addressed by experimental science was the unwarranted assumption of a correspondence between the knower and the world, what he called a "pre-established harmony" (1862) ${ }^{13}$ between mind and nature. He saw the psychological doctrine of vitalism, Naturphilosophie and (his reading of) Kantian philosophy to all be variations on the theme of "philosophies of identity" (Helmholtz 1862, 125). Typified by Hegelian philosophy, the Naturphilosoph endorsed the belief that "the human mind is able, without any guidance from external experience, to think again the thoughts of the creator and to rediscover them by its own inner activity" (Helmholtz 1862, 125). Not only was this approach non-conducive to experimental science, it was seen as hubristic and elitist, as it required a mind equal to that of Hegel or Goethe-a condition that would not have encouraged a broadly collective empirical project. Hegel's own views, Helmholtz claimed, were only popular due to their ability to amaze by way of "strange, abstract phraseology, which was perhaps really understood by but a few of his worshippers" (Helmholtz 1862, 126). Like the leaf-like appendage of Goethe's Urpflanze, Hegel's

\footnotetext{
${ }^{12}$ With the complicated exception of Virchow, who promoted a more socially-based medicine. See Jardine 1997.

13"Pre-established harmony" was not intended to invoke Leibnizian metaphysical connotations but refer instead to the idea of a harmony between the mind of the knower and the object of knowledge, built into the relationship between the two, and allowing the former to access the latter without impediment.
} 
work was ultimately obscure and incommunicable. According to Helmholtz, the artist was subject to the same epistemic vices as the Hegelian and the Kantian who were all three guilty of assuming that the structures and rules of the mind were present in macrocosmic nature and constitutive of scientific knowledge. ${ }^{14}$

\section{iV. Prescriptions to Cure a Naturphilosoph}

For the ills of Naturphilosophie Helmholtz prescribed the practices of cultivating untiring patience, strict adherence to experimental methods, and step-by-step reasoning that prevented jumping to conclusions. It was only through the meticulous and patient conducting of tests that the virtuous scientist could raise a mere hypothesis to the status of law through the careful accumulation of evidence. These admonitions are reminiscent of those associated with the mechanical objectivity identified by Daston and Galison, whose proponents cautioned against interpretation and imprinting pre-conceived notions upon data. By adhering to these virtues the scientist could "let nature speak for itself" and get as close as possible to certain, objective knowledge. These virtues suggest a concern for an accurate scientific representation of the world and a notion of objectivity that emphasized correspondence. Yet, for Helmholtz, there existed also the virtues of structural objectivity.

Daston and Galison classify Helmholtz as a structural objectivist and take his epistemology of signs to be an example of structural objectivity (253). Helmholtz's sign theory took phenomenal experience and empirical knowledge to be built out of sensations that came through the sensory apparatuses as signals or signs, as opposed to re-presentations or mirror

\footnotetext{
${ }^{14}$ Michael Heidelberger argues that it was not ideas per se that Helmholtz reviled but rather, particular assumptions about the human mind's ability to have direct purchase in objective nature. Helmholtz's work in physiology had taught him that scientists were not justified in assuming that the world which caused the stimulations from which perceptions were constructed, was anything like the perceptions themselves. However, experimental science could afford actual, objective knowledge of the relations of things by discovering what elements of phenomena were necessary always and everywhere. Formulating these laws assumed certain ideas like force and matter, as Helmholtz did in his "Memoir." An objective scientist could assume certain ideas, but they had to be well justified. In his earlier days, Kantian justifications of force and matter in terms of their necessity for doing physics vindicated the use of those ideas, though they lacked direct experiential evidence. Their assumption was additionally supported by the practical success of the physical theory that resulted. After the 1860s Helmholtz lessened his reliance upon the Kantian strategy and weighted the justification for ideas more heavily on the successful application of the theories they allowed. Still, in neither case could it have been a ideas as such in virtue of which Naturphilosophie was opposed to experimental science. The problem lay in certain ideas, ones that assumed without warrant a correspondence between mind and phenomenal world. See Heidelberger 1994, esp. 493-94.
} 
images of the world. ${ }^{15} \mathrm{He}$ wrote, "our sensations are but for us only symbols of the objects of the external world, and correspond to them only in some such way as written characters or articulate words to the things they denote" (Helmholtz 1853, 54). He took the relationship between sensational signs and their objective stimulators to be a causal one and the task of science to obtain knowledge of objective relations by translating back from perceptions to the invariances that held between objects. The scientific project strove to translate back to the objective structure of things from the relations in experience. ${ }^{16}$ The language of phenomena, which included such concepts as a Lebenskraft, was unsuited to objective science. The vocabularies of experience contained many inaccuracies and varied between persons. Helmholtz understood his own investigations to have contributed evidence to this epistemological position-in the "Facts in Perception" he argued that what recent physiology showed was that the mode of sensation (and the quotidian vocabularies used to talk about them) did not necessarily correspond to modes of stimuli in the external world. Rather it was, for example, in the case of sensations of tone, the length of the sound wave that determined whether it was a sound or a tactile sensation of vibrations. The categories of our experience were not necessarily the objective categories of the world. Only in precise measurements that applied everywhere and always, irrespective of the sensory organ in question, could one be confident of the objective validity of judgments about sensations. Writ large on the level of epistemology this meant that only abstract relations of signs got beyond subjective experience into the world: the sign theory was intended as a solution to the problem of epistemic access.

Helmholtz was indeed committed to the ethos of structural objectivity, and we may interpret the greater emphasis on communicability in the later Goethe paper as a shift in the weighting of his epistemic virtues even more towards those of structural objectivity. However, contra to the picture offered by Daston and Galison, who depict him as committed solely to structural objectivity, a closer look at his set of epistemic virtues reveal that during his career he espoused and practiced norms characteristic of both mechanical and structural objectivity.

This is a minor point, as Daston and Galison do not insist that structural objectivity arose purely out of the ashes of mechanical, but allow that both these ethics had their adherents at the end of the nineteenth century (50). The more interesting claims that I wish to make in light of what

\footnotetext{
${ }^{15}$ This differs significantly from both the Kantian and Goethean conceptions of the relationship between the knower and known.

${ }^{16}$ I want to emphasize the sense of striving here-for Helmholtz there was no guarantee of achieving correspondence.
} 
has been said about Helmholtz is to suggest that at least one variety of nineteenth-century objectivity arose not from concerns about or in response to a new, active conception of the subject, but from a complex of factors that suggest that the history of objectivity must look beyond philosophical conceptions of the self for the whole story.

In their discussion of the rise of objectivity Daston and Galison claim that the new credo was a response to, and was made possible by the emergence of:

The post-Kantian self $[\ldots]$ active, integrated, and [..] Organized around the dynamic and autonomous will, the self acted on the world, projecting itself outward [...] This is the subjective self of Idealist philosophy, Romantic art, and, as James bears witness, early experimental psychology: a self-a "subject"-equal to and opposed to the objective world. (201)

In light of what has been said regarding Helmholtz's concerns about Goethe and the idealism of Naturphilosophie, I question whether the artistic, Kantian and idealist selves can be grouped against the scientific self on the basis of an active-passive distinction and whether the nineteenth-century move to objectivity is best understood as a response to the threat of an active subject.

According to Daston and Galison, the subjective menace was, "viewed as overactive and prone to impose its preconceptions and pet hypotheses on data" (203) and was represented in the artist as, "authentic, recreating the world in the image of an assertive and indelible self" (246). Daston and Galison take Helmholtz's views on Goethe to be apologetics for active transgressions of this sort. However, I hope that the preceding discussion establishes that Helmhotlz was not kept awake at night by the thought of Goethe qua Romantic in this sense, but Goethe qua naïve poet with naturphilosophisch assumptions. And it was not a matter of Goethe's active re-imaging of the world that would have caused this insomnia.

The argument in Objectivity groups the artist and the idealist together by distinguishing them from earlier passive conceptions of the self characteristic of Enlightenment psychology (199). The threat to knowledge from the scientific self for Locke and other eighteenth-century philosophers of mind was its nature as a passive conglomeration of faculties that simply accepted, and was often fooled by its environment (199). The authors claim that after Kant this was no longer the threat. Yet, this did not seem to be the case for Helmholtz, whose worries about Goethe's complacent artistic intuition looked rather like those that would have plagued Locke. Helmholtz's theory of signs was designed to deal with the concern of accurate epistemic access to the world while remaining 
true to findings in sensory physiology that revealed our cognitive-sensory apparatuses as potentially misleading. Of course eighteenth-century psychologists were not the only ones concerned with issues about the correspondence of ideas to reality-l've already noted that so too were those committed to mechanical objectivity. But the latter group had concerns of a different nature, about an active mind tainting scientific descriptions as opposed to a passive complacent acceptance of the world as presented-the difference may be conceived as that between self-deception and being deceived. Helmholtz's worries resemble those of eighteenth-century psychologists with respect to passive subjects but he is still working with a fundamentally different theory of the mind and of the subject and is motivated by very different social-political concerns. It would seem that the story of objectivity in the nineteenth century is not one of a straight-forward break from the eighteenth century nor is it a simple reinterpretation of past concerns, but is rather a more complicated narrative. Various threads feed into Helmholtz's worries about scientific methods and objectives and they do not easily reduce to concerns over the threat of a particular philosophical conception of the willful self.

\section{AnOther MOMEnt IN the History of ObJectivity}

Helmholtz's worries about Goethe suggest another way to understand the threat from subjectivity in which the investigator, be they the extraordinary artist or Naturphilosoph, problematically assumed that their unaided intellect was sufficient for extracting knowledge of nature. This is a highly moralized framing of the problem, the self on offer here is not metaphysical-philosophical but resides on a more practical-moral level. It captures elements common to the romantic artist as portrayed by Daston and Galison, and to Goethe and the idealist as understood by Helmholtz. The same peremptory self-assurance that Helmholtz attributed to Goethe and the Naturphilosophen may be attributed to the romantic artist as depicted in Objectivity-both scorn the experimental method and take their own mind to be sufficient for accessing truths of nature. This hubristic nonchalance is neither strictly active nor passive but could be expressed either way-the romantic artist, as characterized by Daston and Galison, was highly active, shaping his vistas of the nature according to his will, while the naïve poet was characterized by both Schiller and Helmholtz as a passive spectator who grasps nature through the power of his unaided mind. Whether or not these are legitimate characterizations of Goethe or any romantic is less important for our purposes than the degree to which they were understood by scientists to pose a threat to proper scientific pursuits. Both were interpreted as constitutive of a threat to scientific objectivity in virtue of their shared disrespect for the humility and hard work 
that was needed for scientific knowledge. This de-coupling of the epistemic anxieties and virtues along the lines of activity and passivity suggests that there is more going on in the rise of objectivity in the nineteenth century than Daston and Galison present.

I take it to be the case that for at least one prominent nineteenth-century scientist the threat of an active post-Kantian self was not the catalyst for a turn to objectivity. The dangers of subjectivity for Helmholtz and his anti-idealist colleagues sprang from a conception of an overly self-assured subject that threatened to render science obscurantist and elitist and cause it to stray from its experimental roots. This provoked a turn to a variegated set of epistemic virtues that included admonitions from both mechanical and structural objectivity, indicating a de-coupling of the epistemic anxieties and virtues as presented by Daston and Galison. This threat cannot be disentangled from the situation of mid-nineteenth-century German science, The work of scholars such as Timothy Lenoir, David Cahan and Nicholas Jardine shows us that Helmholtz and his peers were inspired by a social agenda to replace grammar and the classics with mathematics and science as the foundation of German education and push a liberal agenda on a broader political scale. ${ }^{17}$ This agenda was entangled with the images of the idealist and artist as I have here described them and together provoked a turn to a variegated set of epistemic virtues. For Helmholtz, at least, the prominence of philosophies of identity in German science, contemporary scientific research, and the desire to build a liberal society on scientific-rational grounds pushed him to adopt aspects of mechanical and structural objectivity whilst retaining worries about a passive self similar to those of his eighteenth-century predecessors. It does not seem that the threat of the Kantian subject was the primary motivator in his turn to objectivity.

I would suggest that this calls for a re-evaluation of the claim, made by Daston and Galison, that objectivity can be understood through the rise of a particular kind of self, the post-Kantian subject. Daston and Galison's methodology aims to describe the history of objectivity through the history of philosophical conceptions of the self. If we take Helmholtz as a case study of a nineteenth-century scientist concerned with objectivity, his variegated set of motivating concerns and ways of addressing them suggests that the history of objectivity requires more than reference to the history of subjectivity for its explication. The subject of Idealism and the subject of the naïve poet were importantly distinct from the willful subject as typified by the romantic artist, and each inspired different combinations of epistemic virtues. The particular conception of the subject that most worried Helmholtz and his peers was partially determined by

${ }^{17}$ See Cahan 1994, Jardine 1997, Lenoir 1997. 
the professional and political situations that they found themselves in. Understanding some of the motivating concerns for Helmholtz's science and his philosophical foundations for science demonstrates how many and varied are the elements that went into the emergence of objectivity in the nineteenth century. If we do not sufficiently recognize that the contributing factors to the conception and development of epistemic virtues are many and multi-leveled, we will get an impoverished understanding of the concerns of, and solutions employed by, scientists in their search for knowledge.

\author{
DANIELLE HALLET \\ Department of Philosophy \\ University of British Columbia \\ 1866 Main Mall (E370) \\ Vancouver, BC \\ V6T 1 Z1 \\ danih@interchange.ubc.ca
}

\title{
REFERENCES
}

Brain, Robert and Matthew Norton Wise. 1998. Muscles and Engines: Indicator Diagrams and Helmholtz's Graphical Methods. In The Science Studies Reader, ed. Mario Biagioli, 51-66. London: Routledge.

Cahan, David. 1994. The Civilizing Power of Science. In Helmholtz and the Foundations of Nineteenth Century Science, ed. David Cahan, 559-601. Berkeley, CA: University of California Press.

Daston, Lorraine and Peter Galison. 2007. Objectivity. New York: Zone Books.

Goethe, Johann Wolfgang von. 1798. Empirical Observation and Science. In Goethe: The Collected Works: Scientific Studies vol. 12, ed. and trans Douglas Miller, 24-25. Princeton, NJ: Princeton University Press.

Goethe, Johann Wolfgang von. 1807. The Purpose Set Forth. In Goethe: The Collected Works: Scientific Studies vol. 12, ed. and trans Douglas Miller, 63-66. Princeton, NJ: Princeton University Press.

Hatfield, Gary. 1990. Helmholtz: The Epistemology and Psychology of Spatial Perception. In The Natural and the Normative: Spatial Theories of Perception from Kant to Helmholtz, 165-234. Cambridge, MA: MIT Press.

Hatfield, Gary. 1994. Helmholtz and Classicism. In Helmholtz and the Foundations of Nineteenth Century Science, ed. David Cahan 522-58. Berkeley, CA: University of California Press.

Heidelberger, Michael. 1994. Force, Law, and Experiment: The Evolution of Helmholtz's Philosophy of Science. In Helmholtz and the Foundations of Nineteenth Century Science, ed. David Cahan, 461-97. Berkeley, CA: University of California Press. 
Helmholtz, Hermann von. 1853[1971]. On Goethe's Scientific Researches. In Selected Writings of Hermann von Helmholtz, ed. and trans. Russell Kahl, 33-59. Middletown, CT: Wesleyan University Press.

Helmholtz, Hermann von. 1857[1971]. The Physiological Causes of Harmony in Music. In Selected Writings of Hermann von Helmholtz, ed. and trans. Russell Kahl, 75-108. Middletown, CT: Wesleyan University Press.

Helmholtz, Hermann von. 1862[1971]. On the Relation of Natural Science to the Sciences in General. In Selected Writings of Hermann von Helmholtz, ed. and trans. Russell Kahl, 122-43. Middletown, CT: Wesleyan University Press.

Helmholtz, Hermann von. 1878[1971]. The Facts in Perception. In Selected Writings of Hermann von Helmholtz, ed. and trans. Russell Kahl, 115-63. Middletown, CT: Wesleyan University Press.

Helmholtz, Hermann von. 1891[1971]. An Autobiographical Sketch. In Selected Writings of Hermann von Helmholtz, ed. and trans. Russell Kahl, 466-78. Middletown, CT: Wesleyan University Press.

Helmholtz, Hermann von. 1892[1971]. On Goethe's Anticipation of Subsequent Scientific Researches. In Selected Writings of Hermann von Helmholtz, ed. and trans. Russell Kahl, 479-500. Middletown, CT: Wesleyan University Press.

Jardine, Nicholas. 1997. The Mantle of Müller and the Ghost of Goethe: Interactions between the Sciences and Their Histories. In History and the Disciplines: The Reclassification of Knowledge in Early Modern Europe, ed. Donald Kelley, 297-317. Rochester, NY: University of Rochester Press.

Jurkowitz, Edward. 2002. Helmholtz and the Liberal Unification of Science. Historical Studies in the Physical and Biological Sciences (32), 291-317.

Lenoir, Timothy. 1997. Politics of Vision: Optics, Painting, and Ideology in Germany 1845-95. In Instituting Science: The Cultural Production of Scientific Disciplines, 131-78. Palo Alto, CA: Stanford University Press.

Richards, Robert. 2002. The Romantic Conception of Life: Science and Philosophy in the Age of Goethe. Chicago: University of Chicago Press. 